\title{
Facing Malaria Parasite with Mosquito Symbionts
}

\author{
Guido Favia et al.* \\ School of Bioscience $\mathcal{E}$ Biotechnology, University of Camerino, Camerino (MC) \\ Italy
}

\section{Introduction}

Microbial symbiosis is an ubiquitous aspect of insect life and plays a fundamental role in the adaptation of insects to the most diverse environments. A very large proportion of insects are supposed to carry bacterial symbionts (Chaves et al., 2009). The variety of the relationships between symbionts and insects are very wide as well as biological function exerted by the symbionts and their localisation within the host. In fact, some are located within host cells while some others are outside. The genetic modification of microbial symbionts has been identified as novel tools to fight insect pests and vectors of infectious diseases. In this frame, in the last years, the use of manipulated symbiont has attracted a lot of attention for the potential application in the control of mosquito-borne diseases, with particular interest to malaria control.

Malaria still represents a major health problem with particular impact in the developing countries. Even though several control tools are employed for malaria control, such as bed nets, Anti-malarial drugs, insecticides and other vector control measures, the disease continue to exert a dramatic health burden on the world human populations. Consequently, new effective tools for malaria control are expected. Human malaria is transmitted by some mosquito species belonging to the genus Anopheles and methods aimed to control the malaria infection by blocking the transmission from mosquito to humans are particularly attractive.

Recently, quite a lot of attention has been addressed to the so-called Malaria Symbiotic Control (Favia et al., 2008). In fact, more generally, symbiotic microorganisms offer some possibilities for insect pest management strategies and two approaches are particular attractive: The first one implies the disruption of microbial symbionts required by insect pests. The second approach is the manipulation of microorganisms with major impacts on insect traits contributing to their "pest status" for example their capacity to act as vector for diseases like malaria and others. In particular, the paratransgenic approach looks feasible for malaria control.

Paratransgenesis is the genetic modification of insect symbionts to express anti-pathogen molecules within the vector to block pathogen transmission. In case of malaria infection,

*Irene Ricci, Patrizia Scuppa, Claudia Damiani, Paolo Rossi, Aida Capone, Chenoa De Freece, Matteo Valzano, Alessia Cappelli, Michela Mosca and Ulisse Ulissi 
mosquitoes should be "forced" to host symbionts that have been previously manipulated to express effector molecules able to interfere with Plasmodium development, possibly blocking transmission.

In the frame of insect borne diseases, Chagas disease has already proven the feasibility of paratransgenesis in the control of the infection. Vectors of Chagas disease are obligate haematophagous triatomines that feed on vertebrate blood throughout their entire developmental cycle. These insects harbour populations of bacterial symbionts within their intestinal tract, which provide nutrients that insects do not acquire by the blood source. These symbionts have been isolated, cultured outside the host and genetically transformed to express molecules that render the insect refractory to the infection with Trypanosoma cruzi, the etiological agent of Chagas disease (Beard et al., 2001). Once reintroduced in the vector host, the paratransgenic insect vector showed refractoriness to parasite infection.

Thus, also on the basis of impulse related to these very exciting results in paratransgenic approach to control Chagas disease, since few years, some researches have been addressed to the identification microbial symbiont that could be implemented in the development of paratransgenic approach for malaria control.

In this chapter we will give an overview an update of the recent advance in symbiont basedmalaria control.

\section{Best symbiont candidates for malaria control}

For malaria Symbiotic Control (SC), "good" candidates are those microbes residing within the mosquito, particularly those localised in the gut. In fact, malarial gametocytes, ingested by a feeding mosquito, must transform to gametes, fuse to form zygotes, and then, as ookinetes, migrate to the mosquito's midgut epithelium to develop as oocysts that release sporozoites to infect the mosquito's salivary glands. At the Oocysts stage of Plasmodium, the protozoan parasite causing the malaria infection, represents a favourable target for control method like paratransgenesis aimed to interrupt the disease transmission. In fact, in natural conditions, from thousands of gametocytes ingested by the mosquito vector in an infected blood meal, generally less than ten oocysts will develop.

As stated above, paratransgensis has been already proposed to control insect borne diseases. This is the case of Rhodnius prolixus, a triatomine commonly known as the kissing bug, vector of Trypanosoma cruzi the causative agent of the Chagas disease. $R$. prolixus harbours in its gut some bacteria that provide nutrients to the insect. These bacteria have been cultivate outside the host, modified to express specific anti-parasite effector molecules and reintroduced within the vector (Beard et al., 2001). These paratransgenic insects have shown to be unable to transmit the parasite. These evidences have posed the basis for the development of paratransgenic-related strategies, based on gut symbionts, to control insect borne diseases.

In the meanwhile they represent the cornerstone on which to base the development of SC of malaria infection.

The search of gut symbiont has been primarily addressed to the identification of bacteria residing in the mosquito gut. Some studies have described the structure of the bacterial community present in several mosquito species (Demaio et al., 1996; Pidiyar et al., 2002, 
2004; Touré et al., 2000), pinpointing that different mosquito species harbour common bacterial genera (e.g. Pseudomonas, Staphylococcus, Enterobacter, Escherichia), some of which might be cultivated outside the vector and manipulated by the means of genetic tools that are already available.

Cultivability in cell-free media and applicability to genetic transformation are two of the fundamental prerequisite of a "good" symbiont to be applied in paratransgenesis control of insect vectors.

More recently, the application of advanced molecular techniques, led to the identification of bacterial species, never described before, has stable component of the microbiota associated to malaria vectors.

For example in the African malaria vector Anopheles arabiensis two new species have been recently described (Kämpfer et al., 2006a, 2006b). One was named Janibacter anophelis the other Thorsellia anophelis to remark the close relationship with the mosquito host. In particular, T. anophelis has been proposed in malaria paratransgenic control, since this bacterium, by the means of sequencing of major bands generated in Denaturing Gradient Gel Electrophoresis (DGGE) experiments, appears to be dominant in Kenyan populations of Anopheles gambiae, the main African malaria vector (Briones et al., 2008) and dominance is indeed one additional main features required for a symbiont to be employed in paratransgenesis.

The list of bacteria well adapted to malaria vectors midgut has been rapidly growing in the last few years. Among these bacteria two species have been recently described as particularly well adapted to An. gambiae midgut, Pantoea stewartii and Elizabethkingia meningoseptica (Lindh et al., 2008) and thus potentially useful for symbiotic control applications.

Recently, we have identified a Gram-negative $\alpha$-proteobacteria as stably associated to different mosquito species with particular regards to some main malaria vector species (Favia et al., 2007, 2008; Damiani et al., 2008, 2010; Crotti et al., 2009) and its further microbiological and molecular characterization clearly indicate it as belonging to the genus Asaia (Ricci et al. 2011a).

The relationship between Asaia and mosquito is particularly intriguing in the view of paratransgenic applications since this bacterium localizes in the gut (Figure 1), in the salivary glands and in the reproductive organs of both male and female adult mosquitoes. These localizations are important since in the mosquito gut and salivary glands overlaps with that of Plasmodium thus supporting the use of Asaia for paratransgenic applications. The localization in the reproductive organs relates to vertical transmission routes that imply favourable means to introduce modified bacteria in the field (Damiani et al., 2010).

Furthermore, Asaia is easily cultivable in cell-free media, is detectable at all developmental stage of the mosquito and has high prevalence in mosquito populations. These characteristics have indicated Asaia as one of the potentially best bacterial symbiont of malaria vectors to develop paratransgenic protocols to control malaria infection.

Transformation of Asaia was originally achieved by a strain originally isolated from Anopheles stephensi, one of the major Asian malaria vector, and was attempted by using different plasmid vectors. 
Among these, the plasmid pHM2 was the most efficient and transformed Asaia with high efficiency. The gene cassette coding for the green fluorescent protein (Gfp) was cloned into the plasmid vector $\mathrm{pHM} 2$ thus providing an efficiently detectable marker to trace mosquito body colonization. Transformed Asaia cells were found to efficiently express the protein and showed bright fluorescence useful for localization of the symbiotic cells in the insect body detectable by fluorescent confocal laser scanning microscopy (Figures 2 and 3). Furthermore, in laboratory, when we proposed fed mosquitoes by cotton pad soaked in a mixture of sugar and "green" bacteria, nearly $100 \%$ of the recipient populations resulted colonised by the modified Asaia.

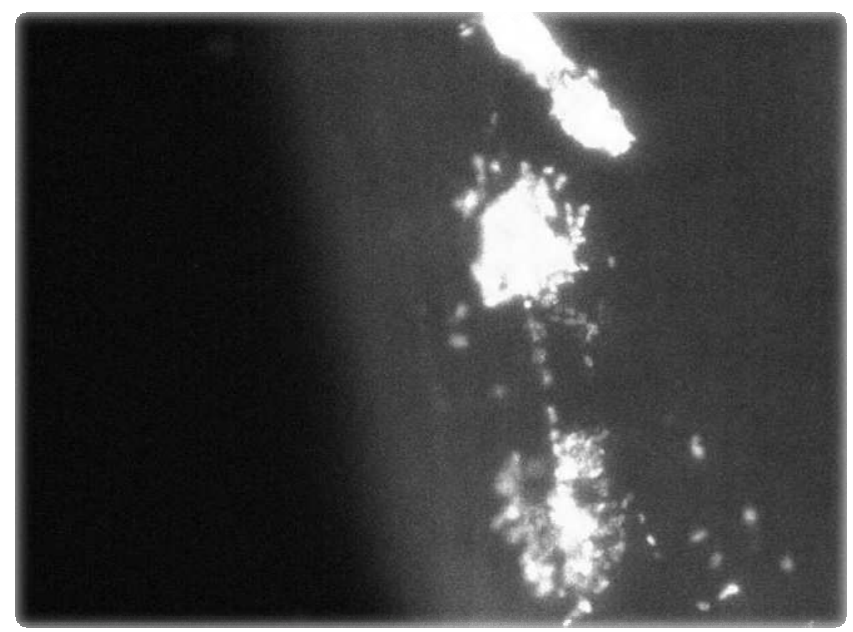

Fig. 1. Asaia bacteria in the gut of an adult An. stephensi mosquito.

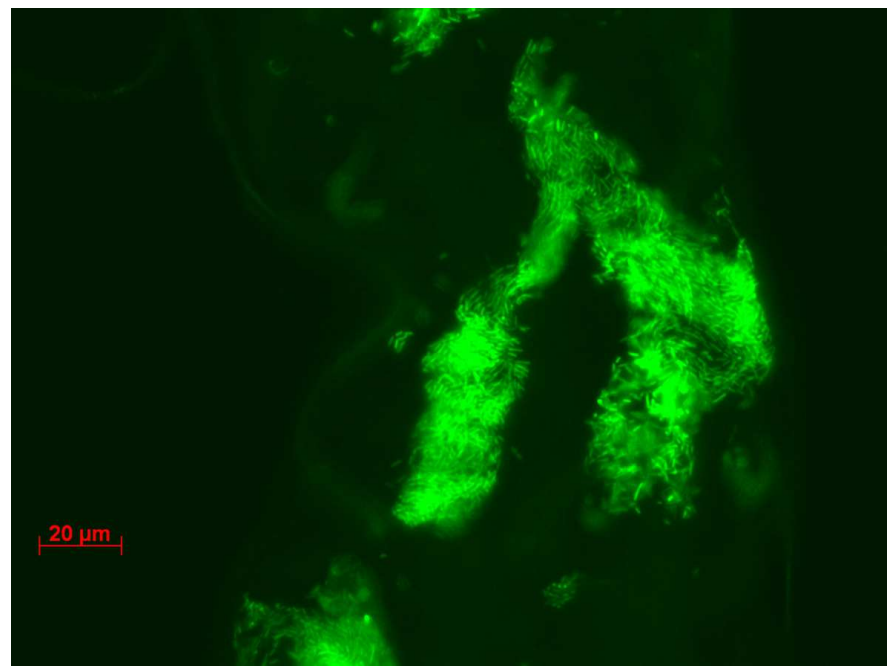

Fig. 2. Asaia strain expressing the green fluorescent protein in the midgut of an Anopheles stephensi female specimen. 


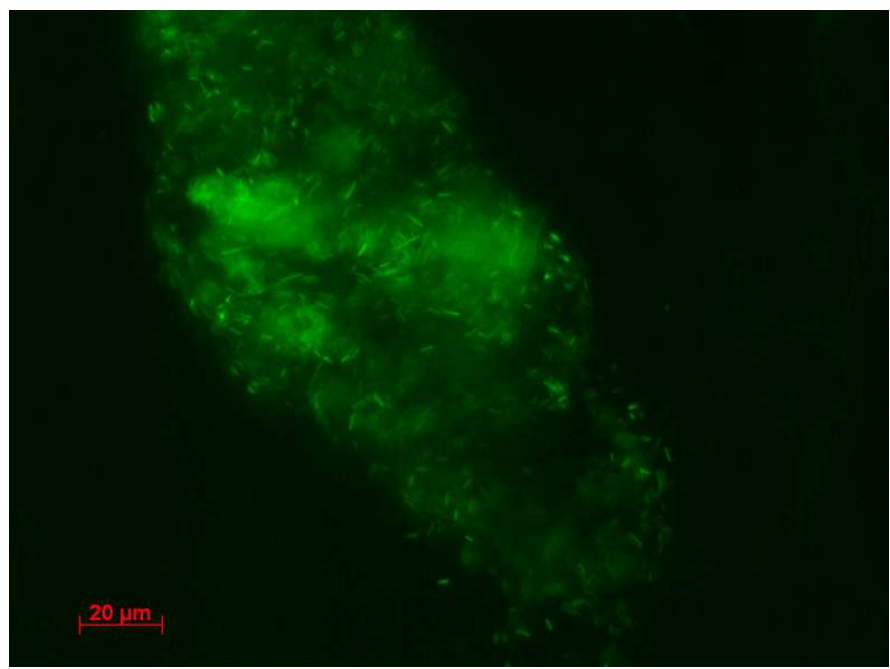

Fig. 3. Asaia strain expressing the green fluorescent protein in the midgut of an An. stephensi male specimen.

\subsection{Effector molecules with anti-Plasmodium effects}

Some molecules have proven to be effective in inhibiting the development of the malaria parasite within the mosquito vector and may be implemented in paratransgenic experiments aimed to block malaria transmission.

Among them has to be mentioned the small dodecapeptide SM1. This peptide is able to interfere with a binding protein of the lumen of the mosquito midgut and salivary glands that is required for Plasmodium invasion. This interference between SM1 and mosquito midgut results in the inhibition of parasite development (Ghosh et al., 2001). A second molecule to be mentioned is the snake venom phospholipase named PLA2 that is able to block Plasmodium development within the mosquito by the inhibition of the association between ookinetes and midgut surface (Zieler et al., 2001).

A third molecule is Scorpine an antimicrobial peptide isolated from the venom of the scorpion Pandinus imperator, with anti-bacterial activity and a potent inhibitory effect on the ookinete and gamete stages of the rodent malaria parasite Plasmodium berghei development (Conde et al., 2000).

Other effector molecules to be mentioned are two single chain antibodies called antiPfNPNA1 and anti-Pbs 21 respectively.

The single-chain antibody PfNPNA-1 is based on a recombinant human monoclonal antibody that specifically recognizes the repeat region (Asn-Pro-Asn-Ala) of the Plasmodium falciparum surface circumsporozoite protein and agglutinates sporozoites (Chappel et al., 2004).

Pbs21 is an ookinete surface protein of $P$. berghei, a rodent's parasite, belonging to a class of sexual stage antigens able to induce in the vertebrate host a transmission-blocking immune 
response. The effectors of this transmission-blocking immunity are antibody molecules directed against particular protein epitopes (Spano et al., 1996). Anti-Pbs 21 may be used in paratransgenic experiment in the murine system to prove the feasibility of the approach.

Some studies have already shown the possibility to use mosquito guts bacteria to deliver anti-Plasmodium effector molecules within the mosquito vector (Riehle and Jacobs-Lorena 2005; Riehle et al., 2007).

In these studies are reported that E. coli bacteria expressing SM1 and PLA2, are able to partially inhibit the parasite development. Very recently, Bisi \& Lampe (2011) described Pantoea agglomerans engineered to express and secrete anti-Plasmodium effector proteins. To this purpose, plasmids that included the pelB or hlyA secretion signals from the genes of related species were constructed and tested for their efficacy in secreting SM1, anti-Pbs21, and PLA2 in P. agglomerans and E. coli.

Very interestingly, P. agglomerans was able to secrete HlyA fusions of anti-Pbs21 and PLA2, and now ongoing experiments are evaluating these strains for anti-Plasmodium activity in infected mosquitoes.

It is worth to remind that parasites tend to have a heterogeneous genome that favours selection of individuals able to overcome barriers such as drugs or possibly effector gene products favouring the insurgence of resistant strains. Thus the possibility to release paratrasgenic mosquito carrying microbial symbionts modified to express several different molecules would circumvent the selection of resistant malaria strains.

The results cited above, represent a clear "proof of principle" about the applicability of paratransgenesis in malaria control.

In this context, the symbiotic bacterium Asaia previously described, may be very successfully implied.

We engineered Asaia strains that were transformed to produce fluorescent proteins; they showed a remarkable capacity to colonize the midgut, reproductive organs ad salivary glands of recipient mosquitoes (Favia et al., 2007; Damiani et al., 2008, 2010). These studies underline the possibility of using this bacterium to express anti-parasite molecules within the mosquito body, to inhibit the transmission of the parasite.

Furthermore, Asaia can be transmitted, vertically to the progeny (by maternal, paternal and trans-stadial routes) and horizontally between mosquito individuals by mating and cofeeding (Favia et al., 2007, 2008; Damiani et al., 2008, 2010).

As stated above, vertical transmission is important because it offers the chance of introducing engineered bacteria into mosquito populations in the field. In An. gambiae it has been proven that vertical transmission occurs by an egg-smearing mechanism, where the extracellular Asaia symbionts are smeared onto the egg surface, thus is quite likely that larvae, after emergence, are infected by the bacteria by feeding on them and on egg remnants (Damiani et al., 2010).

Larvae infection by bacteria in the breeding water, offers a way to spread recombinant bacteria in the field, moreover the vertical transmission of Asaia symbiont would allow the "passage" of recombinant symbionts through the generations. 
Paternal transmission is also important because offers an alternative way to release engineered bacteria in the field in addition to their release in the larval breeding site to contaminate larvae and consequently adults by trans-stadial routes. Indeed, paternal transmission suggests the possibility of releasing not biting male mosquitoes that would be previously colonised with engineered bacteria (Damiani et al., 2010).

Ongoing studies are intended to modify Asaia to produce strains able to express and secrete anti-Plasmodium effector molecules and to test their ability in blocking malaria transmission.

\subsubsection{Not only bacteria}

It is worth to mention that not only bacteria symbiont may find application in paratransgenesis but several evidences indicate that virus, yeast and fungi may also be successfully use.

Ren and collaborators (2008) discovered, cloned and characterized the first known DNV (AgDNV) capable of infection and dissemination in An. gambiae. By the development of an AgDNV-based expression vector to express gene(s) of interest in An. gambiae, an exogenous gene (enhanced green fluorescent protein; EGFP) was expressed in An. gambiae mosquitoes. Wild-type and EGFP-transducing AgDNV virions were able to consistently infect $A n$. gambiae larvae, expressed EGFP was detected in adult tissues such as midgut, fat body and ovaries and were transmitted to subsequent mosquito generations.

This work produced clear evidence that AgDNV could be used as part of a paratransgenic malaria control strategy by transduction of anti-Plasmodium effectors or insect-specific toxins in Anopheles mosquitoes.

In the last few months we have identified the yeast Wickerhamomyces anomalus as stably associated to some malaria vector species localising at the level of midgut and reproductive organs of the host (Ricci et al., 2011b, 2011c). This localization, the possibility to easily manipulate yeast and the chance to express effector molecules in a eukaryotic organism render $W$. anomalus a potential good candidate for paratransgenesis. Interestingly, very often we found in the midgut and reproductive organs of the mosquito a large number of Asaia bacteria in association with a relevant number of $W$. anomalus. This finding may support the idea to use synergistically these two symbionts to release different effector molecules in the mosquito.

We are now proceeding to achieve rapidly a stable transformation system to produce strains of $W$. anomalus able to express and delivery anti-Plasmodium peptides.

Very recently, Fang et al (2011) develop transgenic fungi that kill malaria parasite in the mosquito.

They used the fungus Metarhizium anisopliae to infect mosquitoes through the cuticle. Recombinant strains of M. anisopliae expressing three effector molecules (SM1, a single chain antibody called PfNPNA-1 and an antimicrobial peptide called scorpine) targeting sporozoites during their travel through the hemolymph to the salivary glands were used to infect mosquitoes that had a Plasmodium-infected blood meal eleven days before.

The reduction in sporozoite counts was relevant and even more when using M. anisopliae strain expressing scorpine and an [SM1](8): scorpine fusion protein (with the reduction in 
sporozoite counts of $98 \%$ ). These experiments prove that Metarhizium-mediated inhibition of Plasmodium development could be an additional tool to contrast malaria development within the vector.

\subsubsection{Not only paratransgenesis}

Symbiont may be successfully implied in SC of mosquito vector even without their genetic manipulation. This would be the case of $W$. anomalus. In fact several strains of this yeast produce killer toxins with an antimicrobial effect on a wide spectrum of human pathogens (Séguy et al., 1998; Magliani et al., 2001), including insect-transmitted protozoan parasites such as Leishmania spp. (Savoia et al., 2002). Preliminary data seems to confirm that the $W$. anomalus strain isolated from An. stephensi, produces a killer toxin that is active against some yeast strains (Ricci et al. manuscript in preparation). We will soon test if this killer toxin is active against Plasmodium to verify the possibility to contrast malaria parasite development by the release of this natural killer within mosquito organs.

One mosquito symbiont that has been extensively studied is the alpha-proteobacterium Wolbachia, a very common cytoplasmic symbiont of the majority of insect species, crustaceans, mites, and filarial nematodes (Serbus et al., 2008). Wolbachia are maternally inherited bacteria that inducing cytoplasmic incompatibility in mosquitoes that they use to spread themselves through populations enhancing their transmission (Sinkins, 2004). This ability of self-spreading through mosquito populations attracted a lot of attention in the last few years and has been proposed as a gene drive system for mosquito genetic replacement, for the reduction of population size or for modulating population age structure to reduce disease transmission.

Interestingly, even though the very wide range of insect species naturally infected by Wolbachia, natural infection has never been detected in species belonging to the genus Anopheles (Ricci et al., 2002; Rasgon \& Scott, 2004; Tiawsirisup et al., 2008). On the other hand cultured Anopheles cells can be infected (Jin et al., 2009), this has opened new possibility to study perspectives in the use of endosymbiont to control malaria infection.

An "over-replicating" strain of Wolbachia pipientis named wMelPop has recently been shown to induce immune upregulation and inhibition of pathogen transmission in Aedes aegypti the principal mosquito vector of dengue viruses, thus transient somatic infections of wMelPop were performed by intrathoracic inoculation in An. gambiae. As consequence of these inoculations, up-regulation of several specific immune genes was detected and some of these have shown a direct influence on the development of malaria parasites. Similar results have been achieved when using a stably infected An. gambiae cell line (Kambris et al., 2010).

Other studies have characterized somatic infections of two diverse Wolbachia strains (wMelPop and wAlbB) in An. gambiae. After infection, wMelPop was localized in fat body, head, sensory organs and other tissues but was not detected in midgut and ovaries, even though both Wolbachia strains inhibit $P$. falciparum oocyst in the mosquito midgut.

Even more interestingly, although not virulent in non-bloodfed mosquitoes, wMelPop was found to be virulent for around 12-24 hours post-bloodmeal. All these data strongly indicate that if stable transinfections would behave similarly to somatic infections, Wolbachia could potentially be used as part of a strategy to control malaria-transmitting mosquitoes (Hughes et al., 2010). 
From this point of view, the "Ae. aegypti lesson", can be particularly important. Similar to Anopheles, Ae. aegypti has never been detected as naturally infected by Wolbachia, transinfection of selected strains of Wolbachia in Ae. aegypti can block the development of dengue infection (Walker et al., 2011).

Very recently the wMel Wolbachia strain was introduced into Ae. aegypti from Drosophila melanogaster showing a successfully invasion two natural Ae. aegypti populations in Australia, reaching almost the fixation in a few months after the releases of wMel-infected An. aegypti adults (Hoffmann et al., 2011).

These findings demonstrate that Wolbachia-based strategies can be a successful approach to eliminate dengue infection and a similar approach may be developed to control malaria infection.

\section{Future development and conclusion}

The concept that manipulation of microbial symbionts may represent an important tool to contrast insect pests and insect vectors of infectious diseases is now widely accepted.

Recent studies have also pointed out that is possible to overcome many of the limitations that since some time ago represented strong limitation to this approach, including the difficulty to culture and transform many symbionts. As discussed in the previous paragraph, to date several symbionts of insect pests and vector borne diseases can be cultivated outside the host, manipulated to express specific factors and reintroduced within the host to produce in situ the effector molecules. A very informative example of advanced studies in genetic manipulation of insect symbionts is Rhodococcus rhodnii, a bacterial symbiont of the reduviid bug Rhodnius prolixus. This bacterium, if manipulated appropriately, can be reintroduced to the vector and inhibit the transmission of Trypanosoma cruzi that causes Chagas disease (Beard et al., 2001). Another example regards the bacterium Alcaligenes, a gut symbiont of the sharpshooter Homalodisca coagulata, the vector of Pierce's crop disease (Bextine et al., 2004).

Concerning malaria control, we have described some symbionts that can be cultured outside the mosquito and can be genetically modified to produce specific molecules that have proven to have an inhibitory effect on Plasmodium development. In the last 5 years our group has been focused in the study of symbiosis in mosquito vector. Our group as well as others research units, have indicated few microorganisms that possess a strong potential in the paratransgenic control of mosquito-borne diseases and in the very few last years, the number of parasite of medical and veterinary for which the paratransgenic approach has been proposed as one of the element of an integrated control strategy is increasing as demonstrated by study aimed to develop control method of Leishmania parasite (Hurwitz et al., 2011). However, even if the genetic modification of insect symbionts to inhibit parasite development, is clearly feasible and achievable in laboratories, many concerns need to be properly addressed before this approach can be applicable in the field. Even though the release of paratransgenic mosquito poses much less ethical and safety concerns that the release of genetically modified mosquitoes, for example the release of large-scale transgenic mosquitoes, would cause not only an increase of the nuisance but also the health risk related to other mosquito borne diseases (it is worth to remind that malaria vector mosquitoes may 
transmit other pathogens), the release into the field of modified symbionts needs to be approached with caution since particularly bacteria may spread very rapidly by horizontal transfer and colonize non target organisms with still unknown consequence. On the other hand is possible to argue that there is no reason to believe that any of the effector molecules identified to date will have any effects on non-target organisms (especially higher organisms) being specifically intended against Plasmodium. Still, it is necessary the release of paratransgenic mosquitoes must refer to previous experiences with different Genetically Modified Organisms (GMO) (i.e. GM plants) taking into account indications from different national and international authorities that have already established legal requirements for the safety of these products (Aguilera et al., 2011).

If scientific and ethical concerns have to be properly addressed it is also equally important to address concerns of public perception. First of all it is important to underline that no single approach can be successfully per se but only an integrated control program that will merge the benefits of different type of approaches would be effective in controlling malaria infection. This is true also for the paratransgenic approach.

It is important to involve residents of the malaria affected countries and their government in official way. In this context it is particularly important to widely release the results of safety tests regarding the use of paratransgenic mosquitoes without covering any possible risk associated to the use of such an approach pinpointing precisely the "real balance" between potential benefits and risks associated to the implementation of the paratransgenic strategy. Christopher Boete (2011) has just published the results of an important study about the use of transgenic mosquitoes as a potential approach to interrupt malaria transmission.

This study was performed through a questionnaire addressing questions related to the type of research, the location, the nationality and the perception of the public involvement by scientists. The results indicate that even if malaria researchers agree to interact with a nonscientific audience pinpointing that "they remain quite reluctant to have their research project submitted in a jargon-free version to the evaluation and the prior-agreement by a group of nonspecialists". The study shows the importance of fostering structures and processes that could lead to an improved involvement of an unspecialized public in the debates linking scientific, technological and public health issues in Africa.

One more aspect that is very important to guarantee success to the paratransgenic approach is the capacity to integrate laboratory and field work bringing together competences from different disciplines and context to produce a variegate and efficient bulk of skills that will be more effective that the simple sum of independent competences.

Before any possible field applications, the next step in the assessment of the paratransgenic approach will take advantage by the so-called "semi-field" studies. They can be conducted in mosquito-proof greenhouses that have been termed "malaria spheres" by Knols and collaborators (2002). The green-houses consist in a space-limited ecosystem that recreates an ecological contest with plants, breeding sites etc in which is possible to perform the tests. These test will give important insights about the dynamic of transmission of a due symbiont, in fact releasing subsequent different small numbers of paratransgenic mosquitoes into a malaria sphere containing non-paratransgenic mosquito population it will be possible to determine to the minimum proportion of paratatransgenic insects that need to 
be introduced for the symbiont to spread over the whole population. Furthermore it will be possible to acquire information about the capacity of modified symbiont(s) to compete with the natural microbiota. Moreover, all the data acquired by semi-field studies would also provide valuable parameters for modelling experiments to assess the feasibility of introducing GM-symbionts under true field conditions.

Even though laboratory and field issues have still to be fully overcame, the fast and growing progress recently made in the field of the SC of insect pest and vectors of diseases, induces a relevant optimism that this approach may be applicable for field testing within the next decade thus offering a new weapon to the arsenal against malaria infection.

\section{Acknowledgment}

We wish to thank Luciano Pasqualini for his valuable technical support during the writing of the chapter. Our researches described in this chapter has been supported by the following agencies: agencies Firb-Ideas (grant RBID082MLZ) and Prin 2007 (grant 2007PK2HB7_002), both from the Italian Ministry of University and Research (MIUR), and by the EU-FP7 Capacities-Infrastructure 2008 (grant 228421) to G.F. P.R. benefited of travel grant from the COSTAction FA0701.

\section{References}

Aguilera, J., Gomes, A.R. \& Nielsen K.M. (2011). Genetically modified microbial symbiont as arthropod pest controllers: risk assessment through the European legislations. Journal of Applied Entomology, (August 2011), pp. 494-502.

Beard, C.B., Dotsona, P.M., Pennington, S., Eichler, C., Cordon-Rosales, R. \& Durvasular, V. (2001). Bacterial symbiosis and paratransgenic control of vector-borne Chagas disease. Int. J. Parasitol, (May 2001), pp. 621-627.

Bextine, B., Lauzon, C., Potter, S., Lampe, D. \& Miller, T.A. (2004). Delivery of a genetically marked Alcaligenes sp. to the glassy-winged sharpshooter for use in a paratransgenic control strategy. Curr Microbiol, (May 2004), pp. 327-331.

Bisi, D.C. \& Lampe, D.J. (2011). Secretion of anti-Plasmodium effector proteins from a natural Pantoea agglomerans isolate by using PelB and HlyA secretion signals. Appl Environ Microbiol, (July 2011), pp. 4669-4675.

Boete, C. (2011). Scientists and public involvement: a consultation on the relation between malaria, vector control and transgenic mosquitoes. Trans $R$ Soc Trop Med Hyg (in press).

Briones, A.M., Shililu, J., Githure, J., Novak, R. \& Raskin, L. (2008). Thorsellia anophelis is the dominant bacterium in a Kenyan population of adult Anopheles gambiae mosquitoes. ISME J, (November 2007), pp. 74-82.

Chaves, S., Neto, M. \& Tenreiro, R. (2009). Insect-symbiont systems: from complex relationships to biotechnological applications. Biotechnol. (December 2009), pp. 1753-1765.

Chappel, J.A., Hollingdale, M.R. \& Kang, A.S. (2004). IgG(4) Pf NPNA-1 a human antiPlasmodium falciparum sporozoite monoclonal antibody cloned from a protected individual inhibits parasite invasion of hepatocytes. Hum Antibodies, (December 2004), pp. 91-96. 
Conde, R., Zamudio, F.Z., Rodriguez, M.H. \& Possani L.D. (2000). Scorpine, an anti-malaria and anti-bacterial agent purified from scorpion venom. FEBS Lett, (April 2000), pp. 165-168.

Crotti, E., Damiani, C., Pajoro, M., Gonella, E., Rizzi, A., Ricci, I., Negri, I., Scuppa, P., Rossi, P., Ballarini, P., Raddadi N., Marzorati,. M, Sacchi, L., Clementi E., Genchi, M., Mandrioli, M., Bandi, C., Favia,. G, Alma, A. \& Daffonchio, D. (2009). Asaia, a versatile acetic acid bacterial symbiont, capable of cross-colonizing insects of phylogenetically distant genera and orders. Environ. Microbiol, (September 2009), pp. 3252-3264.

Damiani, C., Ricci, I., Crotti, E., Rossi, P., Rizzi, A., Scuppa, P., Esposito, F., Bandi, C., Daffonchio, D. \& Favia, G. (2008). Paternal transmission of symbiotic bacteria in malaria vectors. Curr. Biol, (December 2008), pp. 1087-1088.

Damiani, C., Ricci, I., Crotti, E., Rossi, P., Rizzi, A., Scuppa, P., Capone, A., Ulissi, U., Epis, S., Genchi, M., Sagnon, N., Faye, I., Kang, A., Chouaia, B., Whitehorn, C., Moussa, G.W., Mandrioli, M., Esposito, F., Sacchi, L., Bandi, C., Daffonchio, D. \& Favia, G. (2010). Mosquito-Bacteria Symbiosis: The Case of Anopheles gambiae and Asaia. Microb Ecol, (June 2010), pp. 644-654.

Demaio, J., Pumpuni, C.B., Kent, M. \& Beier, J.C. (1996). The midgut bacterial flora of wild Aedes triseriatus, Culex pipiens, and Psorophora columbiae mosquitoes. Am. J. Trop. Med. Hyg, (February 1996), pp. 219-223.

Fang, W., Vega-Rodriguez, J., Ghosh, A.K., Jacobs-Lorena, M., Kang, A. \& St Leger, R.J. (2011). Development of transgenic fungi that kill human malaria parasites in mosquitoes. Science, (February 2011), pp. 1074-1077.

Favia, G., Ricci, I., Damiani, C., Raddadi, N., Crotti, E., Marzorati, M., Rizzi, A., Urso, R., Brusetti, L., Borin, S., Mora, D., Scuppa, P., Pasqualini, L., Clementi, E., Genchi, M., Corona, S., Negri, I., Grandi, G., Alma, A., Kramer, L., Esposito, F., Bandi, C., Sacchi, L. \& Daffonchio, D. (2007). Bacteria of the genus Asaia stably associate with Anopheles stephensi, an Asian malarial mosquito vector. Proc. Natl. Sci. U S A, (March 2007), pp. 9047-9051.

Favia, G., Ricci, I., Marzorati, M., Negri, I., Alma, A., Sacchi, L., Bandi, C., Daffonchio, D. (2008). Bacteria of the genus Asaia: a potential paratransgenic weapon against malaria, In:Transgenesis and the Management of Vector-Borne Disease, (Askoy, Serap Ed.), pp. 49-59, ISBN 978-0-387-78224-9, Yale University School of Public Health, New Haven,CT, USA.

Ghosh, A.K., Ribolla, P.E \& Jacobs-Lorena, M. (2001). Targeting Plasmodium Ligands on Mosquito Salivary Glands and Midgut with a Phage Display Peptide Library. Proc Natl Acad Sci U S A, (November 2001), pp. 13278-13281.

Hoffmann, A.A., Montgomery, B.L., Popovici, J., Iturbe-Ormaetxe, I., Johnson, P.H., Muzzi, F., Greenfield, M., Durkan, M., Leong, Y.S., Dong, Y., Cook, H., Axford, J., Callahan, A.G., Kenny, N., Omodei, C., McGraw, E.A., Ryan, P.A., Ritchie, S.A., Turelli, M. \& O'Neill, S.L. (2011). Successful establishment of Wolbachia in Aedes populations to suppress dengue transmission. Nature, (August 2011), pp. 454-457.

Hughes, G.L., Koga, R., Xue P., Fukatsu, T. \& Rasgon, J.L. (2011). Wolbachia infections are virulent and inhibit the human malaria parasite Plasmodium falciparum in Anopheles gambiae. PLoS Pathog, (May 2011), pp. e1002043.

Hurwitz, I., Hillesland, H., Fieck, A., Das, P. \& Durvasula R. (2011). The paratransgenic sand fly: a platform for control of Leishmania transmission. Parasit Vectors, (May 2011), pp. 82. 
Jin, C., Ren, X. \& Rasgon, J.L. (2009). The virulent Wolbachia strain wMelPop efficiently establishes somatic infections in the malaria vector Anopheles gambiae. Appl Environ Microbiol, (May 2009), pp. 3373-3376.

Kambris, Z., Blagborough, A.M., Pinto, S.B., Blagrove, M.S., Godfray, H.C., Sinden, R.E. \& Sinkins S.P. (2010). Wolbachia stimulates immune gene expression and inhibits Plasmodium development in Anopheles gambiae. PLoS Pathog, (October 2010), pp. e1001143.

Kämpfer, P., Terenius, O., Lindh, J.M. \& Faye. I. (2006). Janibacter anophelis sp. nov., isolated from the midgut of Anopheles arabiensis. Int. J. Syst. Evol. Microbiol, (February 2006), pp. 389-392.

Kämpfer, P., Lindh, J.M., Terenius, O., Haghdoost, S., Falsen, E., Busse, H.J. \& Faye, I. Thorsellia anophelis gen. nov., sp. nov., a new member of the Gammaproteobacteria. Int. J. Syst. Evol. Microbiol, (February 2006), pp. 335-338.

Knols, B.G., Njiru, B.N., Mathenge, E.M., Mukabana, W.R., Beier, J.C., Killeen, G.F. (2002) MalariaSphere: a greenhouse-enclosed simulation of a natural Anopheles gambiae (Diptera: Culicidae) ecosystem in western Kenya. Malar J,(December 2002), pp.1-19.

Lindh, J.M., Borg-Karlson, A.K. \& Faye, I. (2008). Transstadial and horizontal transfer of bacteria within a colony of Anopheles gambiae (Diptera: Culicidae) and oviposition response to bacteria-containing water. Acta Trop, (July 2008), pp. 242-250.

Magliani, W., Conti, S., Arseni, S., Frazzi, R., Salati A. \& Polonelli L. (2001) Killer anti-idiotypes in the control of fungal infections. Curr Opin Investig Drugs, (April 2001), pp. 477-479.

Pidiyar, V., Kaznowski, A., Narayan, N.B., Patole, M. \& Shouche, Y.S. (2002). Aeromonas culicicola sp. nov., from the midgut of Culex quinquefasciatus. Int J Syst Evol Microbiol, (September 2002), pp. 1723-1728.

Pidiyar, V.J., Jangid, K., Patole, M.S. \& Shouche, Y.S. (2004). Studies on cultured and uncultured microbiota of wild Culex quinquefasciatus mosquito midgut based on 16s ribosomal RNA gene analysis. The American Journal of Tropical Medicine and Hygiene, (June 2004), pp. 597-603.

Rasgon, J.L. \& Scott, T.W. (2004). Phylogenetic characterization of Wolbachia symbionts infecting Cimex lectularius L. and Oeciacus vicarius Horvath (Hemiptera: Cimicidae). J Med Entomol, (November 2004), pp. 1175-1178.

Ren, X., Hoiczyk, E., Rasgon, J.L. (2008) Viral paratransgenesis in the malaria vector Anopheles gambiae. PLoS Pathog., (August 2008), e1000135.

Ricci, I., Cancrini, G., Gabrielli S., D'Amelio, S. \& Favia G. (2002) Searching for Wolbachia (Rickettsiales: Rickettsiaceae) in mosquitoes (Diptera: Culicidae): large polymerase chain reaction survey and new identifications. J Med Entomol, (July 2002), pp. 562-567.

Ricci, I., Damiani, C., Rossi, P., Capone, A., Scuppa, P., Cappelli, A., Ulissi, U., Mosca, M., Valzano M., Epis, S., Crotti, E., Daffonchio, D., Alma, A., Sacchi L., Mandrioli M., Bandi C. \& Favia, G. (2011). Mosquito symbioses: from basic research to the paratransgenic control of mosquito-borne diseases. Journal of Applied Entomology, (December 2010), pp. 487-493.

Ricci, I., Mosca, M., Valzano, M., Damiani, C., Scuppa, P., Rossi, P., Crotti, E., Cappelli, A., Ulissi, U., Capone, A., Esposito, F., Alma, A., Mandrioli, M., Sacchi, L., Bandi, C., Daffonchio, D. \& Favia G. (2011). Different mosquito species host Wickerhamomyces anomalus (Pichia anomala): perspectives on vector-borne diseases symbiotic control. Antonie Van Leeuwenhoek, (January 2011), pp. 43-50. 
Ricci, I., Damiani, C., Scuppa, P., Mosca, M., Crotti, E., Rossi, P., Rizzi, A., Capone, A. Gonella, E., Ballarini, P., Chouaia, B., Sagnon, N., Esposito, F., Alma, A., Mandrioli, M., Sacchi, L., Bandi, C., Daffonchio, D. \& Favia, G. (2011). The Yeast Wickerhamomyces Anomalus (Pichia Anomala) Inhabits the Midgut and Reproductive System of the Asian Malaria Vector Anopheles Stephensi. Environ Microbiol, (April 2011), pp. 911-21.

Riehle, M.A. \& Jacobs-Lorena, M. (2005). Using bacteria to express and display anti-parasite molecules in mosquitoes: current and future strategies. Insect Biochem Mol Biol, (July 2005), pp. 699-707.

Riehle, M.A., Moreira, C.K., Lampe. D., Lauzon. C. \& Jacobs-Lorena, M. (2007). Using bacteria to express and display anti-Plasmodium molecules in the mosquito midgut. Int. J. Parasitol, (May 2007), pp. 595-603.

Savoia, D., Avanzini C., Conti, S., Magliani, V., Frazzi R. \& Polonelli, L. (2002). In vitro leishmanicidal activity of a monoclonal antibody mimicking a yeast killer toxin. $J$ Eukaryot Microbiol, (July 2002), pp. 319-323.

Séguy, N., Polonelli, L., Dei-Cas, E. \& Cailliez J.C. (1998). Effect of a killer toxin of Pichia anomala to Pneumocystis. Perspectives in the control of pneumocystosis. FEMS Immunol Med Microbiol, (September 1998), pp.145-149.

Serbus, L.R., Casper-Lindley, C., Landmann F. \& Sullivan, W. (2008) The genetics and cell biology of Wolbachia-host interactions. Annu Rev Genet, (December 2008), pp. 683707.

Sinkins, S.P. (2004). Wolbachia and cytoplasmic incompatibility in mosquitoes. Insect Biochem Mol Biol, (July 2004), pp. 723-729.

Spano, F., Matsuoka, H., Ozawa, R., Chinzei, Y. \& Sinden R.E. (1996). Epitope mapping on the ookinete surface antigen Pbs21 of Plasmodium berghei: identification of the site of binding of transmission-blocking monoclonal antibody 13.1. Parassitologia, (December 1996), pp. 559-563.

Tiawsirisup, S., Sripatranusorn, S., Oraveerakul. K. \& Nuchprayoon S. (2008). Distribution of mosquito (Diptera: Culicidae) species and Wolbachia (Rickettsiales: Rickettsiaceae) infections during the bird immigration season in Pathumthani province, central Thailand. Parasitol Res, (March 2008), pp. 731-735.

Touré, A.M., Mackey, A.J., Wang, Z.X. \& Beier, J.C., (2000). Bactericidal effects of sugar-fed antibiotics on resident midgut bacteria of newly emerged anopheline mosquitoes (Diptera: Culicidae). J. Med. Entomol, (March 2000), pp. 246-249.

Walker, T., Johnson, P.H., Moreira, L.A., Iturbe-Ormaetxe, I., Frentiu, F.D., McMeniman, C.J., Leong, Y.S., Dong, Y., Axford, J., Kriesner P., Lloyd, A.L., Ritchie, S.A., O'Neill, S.L. \& Hoffmann A.A. (2011). The wMel Wolbachia strain blocks dengue and invades caged Aedes aegypti populations. Nature, (August 2011), pp. 450-453.

Zieler, H., Keister, D.B., Dvorak, J.A. \& Ribeiro J.M.(2001) A Snake Venom Phospholipase a(2) Blocks Malaria Parasite Development in the Mosquito Midgut by Inhibiting Ookinete Association with the Midgut Surface. J Exp Biol, (December 2001), pp. 4157-4167. 


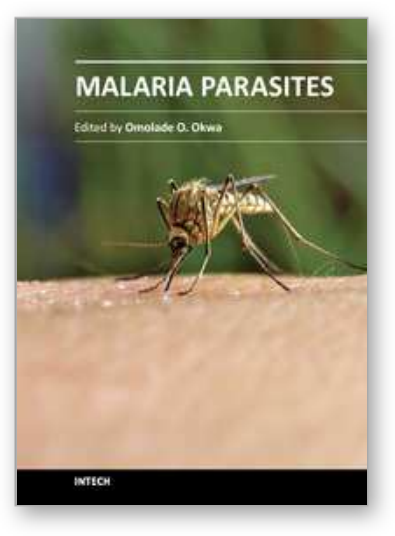

\author{
Malaria Parasites \\ Edited by Dr. Omolade Okwa
}

ISBN 978-953-51-0326-4

Hard cover, 350 pages

Publisher InTech

Published online 30, March, 2012

Published in print edition March, 2012

Malaria is a global disease in the world today but most common in the poorest countries of the world, with $90 \%$ of deaths occurring in sub-Saharan Africa. This book provides information on global efforts made by scientist which cuts across the continents of the world. Concerted efforts such as symbiont based malaria control; new applications in avian malaria studies; development of humanized mice to study P.falciparium (the most virulent species of malaria parasite); and current issues in laboratory diagnosis will support the prompt treatment of malaria. Research is ultimately gaining more grounds in the quest to provide vaccine for the prevention of malaria. The book features research aimed to bring a lasting solution to the malaria problem and what we should be doing now to face malaria, which is definitely useful for health policies in the twenty first century.

\title{
How to reference
}

In order to correctly reference this scholarly work, feel free to copy and paste the following:

Guido Favia, Irene Ricci, Patrizia Scuppa, Claudia Damiani, Paolo Rossi, Aida Capone, Chenoa De Freece, Matteo Valzano, Alessia Cappelli, Michela Mosca and Ulisse Ulissi (2012). Facing Malaria Parasite with Mosquito Symbionts, Malaria Parasites, Dr. Omolade Okwa (Ed.), ISBN: 978-953-51-0326-4, InTech, Available from: http://www.intechopen.com/books/malaria-parasites/facing-malaria-parasite-with-mosquito-symbionts-

\section{INTECH}

open science | open minds

\section{InTech Europe}

University Campus STeP Ri Slavka Krautzeka 83/A 51000 Rijeka, Croatia Phone: +385 (51) 770447 Fax: +385 (51) 686166 www.intechopen.com

\author{
InTech China \\ Unit 405, Office Block, Hotel Equatorial Shanghai \\ No.65, Yan An Road (West), Shanghai, 200040, China \\ 中国上海市延安西路65号上海国际贵都大饭店办公楼405单元 \\ Phone: +86-21-62489820 \\ Fax: +86-21-62489821
}


(C) 2012 The Author(s). Licensee IntechOpen. This is an open access article distributed under the terms of the Creative Commons Attribution 3.0 License, which permits unrestricted use, distribution, and reproduction in any medium, provided the original work is properly cited. 